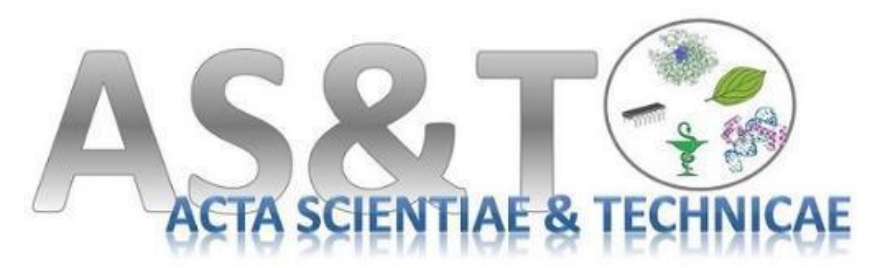

\title{
Serviço social e matriciamento no núcleo de apoio à saúde da família
}

\author{
Camilla Chagas Silva França ${ }^{1}$, Flávio Vaz Machado ${ }^{2}$, Ana Paula Cunha Pereira ${ }^{1}$, Angela Schächter \\ Guidoreni $^{1}$, Alex Aragão Couto ${ }^{1}$, Ilda Cecília Moreira da Silva ${ }^{1}$
}

\section{AUTHOR AFILIATIONS}

1 - Centro Universitário de Volta Redonda - UniFOA (Av. Paulo Erlei Alves Abrantes, 1325 - Três Poços, Volta Redonda - RJ, 27240-560).

2 - Universidade Federal do Estado do Rio de Janeiro - UNIRIO (Av. Pasteur, 296 - Urca, Rio de Janeiro RJ, 22290-250).

\section{CONTACT}

Ilda.silva@foa.org.br

\begin{abstract}
This article deals with the role of Social Service in the Family Health Support Center. The study is based on the assumption that other health professions can grasp the dimensions that constitute the professional competence of the Social Worker. The aim of this study is to reflect on the role of Social Work in the matrix support of the Family Health Support Center and the possibilities for consolidating joint social intervention with the Family Health Strategy. The practice of health cannot be alienating in the pedagogical interpretation. Thus, it becomes possible to think and propose projects that provide the execution of the teaching-learning process in order to reach children, adolescents, adults, pregnant women, the elderly and the disabled.
\end{abstract}

Keywords: Social Service, Socio-educational dimension, Matrix Support.

\section{RESUMO}

O presente artigo versa sobre o papel do Serviço Social no Núcleo de Apoio à Saúde da Família. O estudo parte do pressuposto de que outras profissões da saúde podem apreender das dimensões constitutivas da competência profissional do Assistente Social. O objetivo desde estudo é refletir sobre o papel do Serviço Social no matriciamento do Núcleo de Apoio à Saúde da Família e as possibilidades na consolidação da intervenção social conjunta com a Estratégia de Saúde da Família. Entende-se que a prática da saúde não pode ser alienante na interpretação pedagógica. Assim, torna-se possível pensar e propor projetos que proporcionam a execução do processo de ensino-aprendizagem de modo a alcançar a crianças, adolescentes, adultos, gestantes, idosos e deficientes. 
Palavras-chave: Serviço Social, Dimensão socioeducativa, Apoio Matricial.

\section{INTRODUÇÃO}

Esta pesquisa se ancora em uma preocupação particular: na relevância do papel do Serviço Social no matriciamento do Núcleo de Apoio à Saúde da Família (NASF) junto às equipes de Saúde da Família. Tal preocupação surgiu, devido à ausência do Assistente Social na composição da equipe mínima que trata da Saúde da Família e da Atenção Primária a Saúde (APS) que, por sua vez, contribui para atender as expressões da questão social mais complexas, muitas vezes observadas no cotidiano ligado ao campo da saúde.

O estudo parte do pressuposto de que outras profissões da saúde podem apreender das dimensões constitutivas da competência profissional do Assistente Social, as quais se materializam em movimentos dialógicos que podem descortinar a realidade e suas múltiplas mediações, estabelecendo como fio condutor as construções horizontais na relação entre gestor, equipe de Saúde da Família e equipe do NASF.

Nossa expectativa é contribuir para a produção científica do tema abordado. Nesse sentido, este artigo tem como objetivo refletir sobre o papel do Serviço Social no matriciamento do NASF e as possibilidades na consolidação da intervenção social conjunta com a Estratégia de Saúde da Família (ESF).

Este estudo utilizou-se da metodologia integrativa por meio da revisão da literatura, por 
se tratar de um método que viabiliza a análise da produção científica de modo sistemático e amplo, tendo como produto final o estado atual do conhecimento.

A fim de refletir sobre o Assistente Social como um profissional essencial na prática em saúde, este artigo está estruturado em três linhas principais: Inicialmente no Serviço Social enquanto profissão em saúde, a dimensão intelectual na (i) materialização da prática, seguido dos avanços da saúde e a emergência do Assistente Social como profissional generalista e matriciador.

\section{O ASSISTENTE SOCIAL COMO} PROFISSIONAL LEGITIMADO NO ÂMBITO DA POLÍTICA DE SAÚDE

É desejável nesta pesquisa compreender de que maneira o Assistente Social está

contextualizado historicamente como profissional legitimado no âmbito das políticas sociais, dentre elas a política de saúde. O surgimento e desenvolvimento do Serviço Social no Brasil aconteceram no século XIX, na década de 1930 a 1945, onde a profissão recebeu grande influência europeia e embora a saúde não tivesse visibilidade como espaço profissional, a formação acadêmica continha disciplinas relacionadas à saúde (Bravo; Matos 2007, p. 198).

A expansão da categoria a partir de 1945 abarcou o seu crescimento na área da saúde, principalmente nos hospitais e ambulatórios, vinculado às perspectivas fragmentárias, individuais, assistencialistas e submetido à figura do médico (BRAVO, 2007, p. 33). O Assistente Social era visto como um mediador cujas ações objetivavam o ajustamento dos indivíduos e a normatização da clientela. (Santos; Lanza; Carvalho, 2011, p.19).

Esse crescimento somado ao aprofundamento do capitalismo no Brasil, representou a substituição da influência europeia pela norte-americana e refletiu a nível da formação profissional na alteração curricular. "O marco dessa mudança de influência situa-se no Congresso Interamericano de Serviço Social realizado em 1941, em Atlantic City (EUA)" (Bravo; Matos 2007, p.198).

Cabe ressaltar outro fator importante para a ampliação do campo de trabalho na saúde, em 
função do objeto desta pesquisa, ou seja, o “novo" conceito de saúde, elaborado em 1948 pela Organização Mundial de Saúde (OMS) ${ }^{1}$ que principiou conteúdos preventistas e educativos e consolidou a tarefa educativa do Assistente Social. Sua intervenção caracterizava ações como: triagem ou seleção, encaminhamentos, concessão de benefícios e orientação previdenciária à clientela. Tratava-se de ações paliativas e caritativas, com vista à execução das políticas sociais para manter a ordem entre Estado e sociedade.

Para o Serviço Social Brasileiro, o movimento de reconceituação do Serviço Social da América Latina nos anos 1960 a 1975 deu seus

primeiros passos em direção ao redimensionamento e amadurecimento profissional. Havia uma crítica ao conservadorismo profissional e essa reavaliação interna indagou o Serviço Social tradicional, vinculado ao modelo americano, bem como seus fundamentos, compromissos éticos e políticos, sua ação e formação.

Para entender a reconceituação não basta contrapor o “novo" ao "velho" serviço social. É muito simplista, como se houvesse existido somente uma modernização, um aggiornamento de técnicas, que teria sentido na medida em que pudesse ter trazido mais eficiência ou eficácia à atividade profissional. É preciso ir aos fundamentos da reconceituação como um paradigma crítico de análise e de estratégias socioprofissionais (Faleiros 2005, p. 22).

Por conseguinte, protagonizou ao final da década de 1980 e início de 1990 a ponte para a denominada vertente de intenção de ruptura, onde o Serviço Social incorporou matrizes teóricas e metodológicas, e influenciou documentos fundamentais para a profissão como o Código de Ética Profissional de 1993, a Lei de Regulamentação da profissão de 1993, a criação das atuais diretrizes curriculares de 1996 e o Projeto Ético Político-Profissional.

Segundo Bravo (2007, p.95), a saúde a partir da década de 1980 inscreveu novos atores sociais e deixou de ser apropriada apenas pelos técnicos trazendo implicações para a dimensão política e democrática.

Os autores Bravo \& Matos (2007, p. 205206) defendem que o Serviço Social chega à década de 1990 ainda distante do Movimento de Reforma Sanitária. Na compreensão dos autores, em decorrência da investida neoliberal na saúde, 
o projeto de saúde articulado ao mercado ou projeto privatista, e o projeto da reforma sanitária requeriam diferentes respostas do Serviço Social. De um lado ações fiscalizatórias, assistencialistas e individuais, e do outro, ações democráticas, interdisciplinares e de cunho democrático.

Resumidamente as ponderações explicitadas neste item, nos mostra a complexidade dos desafios presentes no cotidiano das ações profissionais no campo da saúde. Especificamente sobre a questão central que problematizamos neste artigo, qual seja, o papel do Serviço Social no matriciamento do NASF, torna-se imprescindível trazer a discussão sobre a dimensão socioeducativa do Serviço Social, visto que este espaço sócio ocupacional demanda ações nesta direção.

\section{A DIMENSÃO SOCIOEDUCATIVA DO} SERVIÇO SOCIAL: AVANÇANDO INTELECTUALMENTE NA (I) MATERIALIZAÇÃO DA PRÁTICA

Neste item, abordaremos os principais elementos constitutivos da dimensão socioeducativa do Serviço Social e algumas contribuições para a intervenção profissional. A rigor, o Serviço Social se constituiu sob influência do movimento de reconceituação e intenção de ruptura da profissão como uma área de produção do conhecimento apoiada por agências públicas de fomento à pesquisa, como por exemplo, o Conselho Nacional de Desenvolvimento Científico e Tecnológico (CNPq), a Coordenação de Aperfeiçoamento de Pessoal de Nível Superior (Capes), dentre outros.

Marsíglia (2007, p. 383-384) discorre sobre a prática profissional como possibilidade para a produção do conhecimento e eleva o Serviço Social como uma profissão de pesquisadores e formadores sob o viés da "reflexão contínua sobre sua prática" tão importante quanto à pesquisa acadêmica.

Dentro desta perspectiva, Netto (1992, p.28) acrescenta que historicamente "um mercado não se estrutura para $\mathrm{o}$ agente profissional mediante as transformações ocorrentes no interior do seu referencial ou no marco de sua prática; antes, estas transformações expressam a estruturação do mercado de trabalho". Costa (2007, p.305) complementa: “uma profissão não 
se constitui para criar um dado espaço na rede socio-ocupacional, mas é a existência deste espaço que leva à constituição profissional".

Alves \& Aerts (2011, p. 321) salientam que as ações pedagógicas por elas denominadas como ações educativas são "uma prática social, devendo ser centrada na problematização do cotidiano, na valorização da experiência de indivíduos e grupos sociais e na releitura de diferentes realidades".

O paradigma cartesiano e da medicina científica no início do século $\mathrm{XX}$ fragmentou o conhecimento e dividiu os trabalhadores da saúde e os da educação. O primeiro formado para intervir diretamente na saúde com diagnóstico e tratamento, e o segundo no desenvolvimento de ações educativas que obedeciam a padrões de conduta, sem considerar os problemas cotidianos dos indivíduos. (ALVES; AERTS, 2011, p. 320).

As ações educativas eram pouco valorizadas e compuseram os currículos na perspectiva de responsabilizar a população por seus problemas e manter relações de caráter narrativo.
Para Freire (2005), trata-se da denominada "educação bancária", onde o ensino tradicional estava centrado na transmissão das informações. $\mathrm{O}$ educador deposita $\mathrm{o}$ conhecimento e o educando se torna um depositário passivo do conhecimento, uma relação camuflada de diálogo e de apreensão da realidade nos conteúdos.

Nesse sentido, as ações pedagógicas podem ser estimuladas como uma prática social por meio do trabalho interdisciplinar. Bravo \& Matos (2007, p. 212) observam à necessidade de produzir espaços que discutam "a importância da produção do conhecimento sobre o Serviço Social nas diferentes áreas de especialização da prática médica".

São ações pedagógicas no NASF: reunião de matriciamento; elaboração de materiais de apoio para educação permanente; construção de um Projeto Terapêutico Singular; atendimento domiciliar compartilhado; atendimento individual compartilhado; atendimento individual específico; ações intersetoriais e educação permanente. 
Dentre as potencialidades do Serviço Social em um NASF, pode-se assinalar a ampliação do olhar sobre saúde e o trabalho interdisciplinar. No bojo de seus objetivos o desenvolvimento de ações que garantam o acolhimento e incentivem o fortalecimento da autonomia, a participação popular e a promoção da cidadania (Brasil 2009).

Para Iamamoto (2004, p.11), é atributo desta profissão ${ }^{2}$ que trabalha "na transversalidade das múltiplas expressões da questão social”.

Iamamoto (2006) também discute duas dimensões na intervenção profissional: a primeira material-assistencial incorporada através benefícios, programas, projetos e serviços, e a segunda auferindo na subjetividade dos sujeitos de sua intervenção.

[...] o assistente social não trabalha só com coisas materiais. Tem também efeitos na sociedade como um profissional que incide no campo do conhecimento, dos valores, dos comportamentos, da cultura, que, por sua vez, têm efeitos reais interferindo na vida dos sujeitos (Iamamoto, 2006, p.68).

A dimensão socioeducativa do Serviço Social é inquestionável nos diferentes espaços sócio-ocupacionais, pois é uma profissão socialmente determinada. Abordaremos a seguir, uma sistematização dos avanços da saúde e da justaposição do trabalho entre NASF e ESF.

\section{OS AVANÇOS DA SAÚDE E A EMERGÊNCIA DO ASSISTENTE SOCIAL COMO PROFISSIONAL GENERALISTA E MATRICIADOR}

No contexto da saúde pública, para a Constituição Federativa (Brasil 1988), a saúde é conceituada dentro de um conjunto de ações integradas aos cidadãos, e compõe o tripé da Seguridade Social: as políticas de saúde, assistência social e previdência social. Decerto a Carta Magna Brasileira foi um marco para a saúde no Brasil incorporando a visão do movimento sanitário ao tornar o acesso universal, não mais contributivo e com atendimento integral.

A partir de então, as ações e serviços públicos de saúde passaram a compor uma rede regionalizada e hierarquizada, sob as diretrizes da descentralização com financiamento em cada esfera de governo, participação da comunidade e 
participação das instituições privadas de maneira complementar.

Já o Sistema Único de Saúde (SUS), além de ser visto como um legado da reforma sanitária, preconiza a saúde como direito fundamental do ser humano e dever do Estado. Está regulamentado pela Lei 8.080/90 (Brasil $1990 a)^{3}$ e Lei $8.142 / 90$ (Brasil 1990b) ${ }^{4}$ e considerado de extrema relevância para a proteção social e para a saúde pública brasileira, com a expansão da consciência sanitária e novas bases para a saúde no país. Com a ampliação do conceito de saúde sua completude ultrapassa a assistência médica e contempla o essencial à dignidade da condição humana.

Indubitavelmente a saúde está configurada de acordo com a organização social e econômica do país, e expressa os determinantes e condicionantes como: condições de trabalho, habitação, saneamento básico, alimentação, meio ambiente, educação, transporte, lazer e o acesso aos bens e serviços essenciais de qualidade.

Concordando com o acesso universal e igualitário aos serviços de saúde no Brasil, o Ministério da Saúde estabelece o Programa de
Agentes Comunitários de Saúde (PACS) em 1991, e o Programa Saúde da Família (PSF) em 1994, com a finalidade de conferir maior cobertura à família, "sob a influência de outros países que prestam assistência à família como Canadá, Suécia e Inglaterra" (Rosa; Labate, 2005, p. 1030).

Sob os parâmetros da Política Nacional de Atenção Básica (PNAB), aprovada pela portaria $n^{\circ}$ 648, de 28 de março de 2006, que institui a revisão de diretrizes e normas para organização da atenção básica para o Programa Saúde da Família (PSF) e o Programa de Agentes Comunitários de Saúde (PACS), o PSF deixa de ser visto como um Programa e consolida-se como uma estratégia prioritária para a reorganização da atenção básica no Brasil (Brasil 2006).

A ESF surge como um importante componente estruturante do sistema de saúde brasileiro, com a proposta de reorganizar o modelo de atenção no SUS. É a porta de entrada dos usuários e o seu pressuposto é "reorganizar a prática de atenção à saúde em novas bases e substituir o modelo tradicional, levando a saúde 
para mais perto das famílias [...]" (BRASIL, 2009, p. 9).

As equipes Saúde da Família (eSF) são compostas por no mínimo: um médico da família, um enfermeiro, um auxiliar de enfermagem e agentes comunitários de saúde. Podendo compor ainda um dentista e um auxiliar ou técnico em saúde bucal, estendendo para a equipe de Saúde Bucal.

Observa-se que na Portaria $\mathrm{n}^{\mathrm{o}} 2.436$ de 21 de setembro de $2017^{5}$, o Assistente Social não ganha espaço no trato social da equipe mínima da ESF preconizada pela PNAB, no entanto reserva seu papel fundamental na viabilização dos direitos sociais dos usuários da saúde.

Tais equipes podem ser compreendidas como a referência de saúde para a população adscrita, e sua atuação acontece, essencialmente, nas Unidades Básicas de Saúde da Família (UBSF), nas casas e nos espaços comunitários.

Cada equipe é responsável pela longitudinalidade, integralidade e vigilância integral à saúde da população de sua área.

Para ampliar as ações da Atenção Primária à saúde no Brasil, o Ministério da Saúde criou os Núcleos de Apoio à Saúde da Família (NASF), através da Portaria MS nº154 de 24 de janeiro de 2008, com a finalidade de ampliar a abrangência, o alvo e a resolutividade das ações da Atenção Básica.

Cabe destacar a Declaração de Alma Ata, documento síntese da Conferência Internacional sobre Cuidados Primários de Saúde de 1978, que através da Organização Pan-Americana de Saúde (OPAS) e Organização Mundial de Saúde (OMS), enfatizaram o investimento em recursos humanos como questão primordial na implementação da APS. (OPAS/OMS 2005).

Esses núcleos são compostos por equipes onde os profissionais de diversas áreas e especialidades desenvolvem ações conjuntas com as equipes Saúde da Família, e são definidas pelos gestores municipais com observação aos dados epidemiológicos, estrato territorial, necessidades locais e das ESF. São possibilidades de composição do NASF: Assistente Social; Profissional Educação Física; Farmacêutico; Fisioterapeuta; Fonoaudiólogo; profissional com formação em arte e educação (arte educador); Nutricionista; Psicólogo; Terapeuta Ocupacional; 
Médico Ginecologista/obstetra; Médico

Homeopata; Médico Pediatra; Médico

Veterinário; Médico Psiquiatra; Médico

Geriatra; Clínica Médica; Médico do Trabalho;

Médico Acupunturista; Profissional de Saúde

Sanitária (profissional graduado ou pósgraduado em saúde pública ou coletiva). Ou seja, uma equipe multiprofissional que abrange diversas áreas do conhecimento em saúde e pressupõe nesta equipe o Assistente Social.

Por conseguinte, o NASF destaca-se pelas estratégias de apoio matricial que lidam com as complexas realidades de cada equipe Saúde da Família vinculada ao núcleo e inclui equipes multidisciplinares que dialogam com as práticas e saberes, dentre elas integra o Assistente Social na composição do trabalho.

Nas atividades do NASF cada profissional necessita construir estratégias para lidar com as demandas e necessidades sanitárias, e inserir-se em práticas integradas de apoio no campo da saúde coletiva. Tal espaço tende a privilegiar ações de ensino profissional, visto que "pensar para além das questões de cunho biológico, é ainda, uma fragilidade para os trabalhadores das chamadas ciências da saúde" (Machado et al. 2019; Santos, Lanza 2014, p.240).

É impraticável abordar esses avanços significativos para a construção da saúde ampliada no Brasil sem problematizar a ESF como espaço de trabalho do Assistente Social, tendo em vista a legitimidade do Serviço Social enquanto profissão com competência técnica, teórica e política para atuar nas políticas de seguridade social, dentre elas as políticas de saúde, somado à militância CRESS/CFESS pela inserção do Assistente Social na composição das equipes básicas da ESF.

Das práticas que envolvem o Serviço Social no cotidiano das atribuições e competência profissional, devem estar pautados os fundamentos teórico-metodológicos, éticopolíticos e técnico-operativos da profissão.

O Assistente Social atua nas expressões da questão social e no modo como elas se relacionam com a política social, “mediação incontornável na constituição do trabalho profissional" (IAMAMOTO, 2007b, p.185).

É neste campo de tensão que surgem questionamentos sobre: Quais são as ações 
socioeducativas realizadas pelo Assistente Social do NASF às eSF? Como acontece a articulação social com os profissionais da ESF? A contribuição profissional promove a ampliação da capacidade do cuidado nas dimensões que o trabalho em saúde engendra?

Avaliamos que o exercício profissional do Assistente Social na saúde requer uma leitura crítica e propositiva da realidade associada à defesa intransigente dos direitos dos cidadãos. As práticas da saúde são organizadas a partir da integração das ações de prevenção, promoção e recuperação da saúde. Considerando a intervenção curativa e o processo de fortalecimento da autonomia e da organização pessoal do usuário, entre outros.

A profissão de Serviço Social está inserida na divisão social e técnica do trabalho, e “se configura e se recria no âmbito das relações entre o Estado e a Sociedade, fruto de determinantes macrossociais que estabelecem limites e possibilidades ao exercício profissional" (Iamamoto, 2007a, p. 19).

O aspecto formativo da profissão e sua historicidade estão diretamente associados à efetivação dos princípios e diretrizes da política de saúde, a exemplo, a integralidade da atenção à saúde.

Nessa perspectiva, as demandas sociais manifestam-se de diversas formas na dinâmica de trabalho do Assistente Social. Sendo assim:

As ações a serem desenvolvidas pelos assistentes sociais devem transpor o caráter emergencial e burocrático, bem como ter uma direção socioeducativa por meio da reflexão com relação às condições sócio-históricas a que são submetidos os usuários e mobilização para a participação nas lutas em defesa da garantia do direito à Saúde (Cfess, 2010, p. 43).

A inclusão do Serviço Social no NASF está em consonância com os princípios éticos e políticos da profissão. São importantes as ações que garantam a escuta e o acolhimento dos usuários, e, por conseguinte, articulações integradas aos setores sociais diversos, redes e instituições que configuram a intersetorialidade.

Em linhas gerais, o Assistente Social no NASF, através de um conjunto de práticas e saberes amplos compõe a interlocução com outras categorias profissionais e desenvolve o cotidiano 
de trabalho numa visão mais abrangente que contempla aspectos sociais, culturais e econômicos.

O profissional de Serviço Social tem como finalidade a leitura crítica e propositiva dos aspectos sociais, econômicos e culturais que interferem na relação saúde-doença, e a partir dessa função social formular estratégias que efetivem os direitos sociais e garantam respostas às demandas apresentadas pelos usuários da saúde.

Portanto, vale a pena retomar a reflexão sobre a formação generalista do Assistente Social que mediante uma prática de integralidade "atua no processo de compreensão, intervenção e planejamento e execução de Projetos Terapêuticos Singulares voltados à promoção do cuidado no processo saúde-doença" (Cartilha NASF 2018).

É na perspectiva da atenção integral que o profissional de Serviço Social estrutura seu processo de trabalho no interior das equipes de saúde. Com uma abordagem individual e coletiva constrói sua prática na perspectiva do direito e da ampliação da cidadania contribuindo, com um aporte teórico metodológico sobre o processo saúde-doença, para o avanço das reflexões e possibilidades de atuação interdisciplinar no cuidado à saúde (MOURÃO et al. 2007, p. 374).

Dentro dessas premissas, Bravo \& Costa (2007, p. 213) reafirmam que "as novas diretrizes de diversas profissões têm ressaltado a importância de formar trabalhadores de saúde para o Sistema Único de Saúde com visão generalista e não fragmentada".

A partir da revisão de literatura, atrelada aos estudos já existentes sobre a questão, o dilema se faz presente quando ao Assistente Social é designada uma práxis acrítica e normativa construída historicamente pela divisão do trabalho coletivo em saúde, e Netto (1992) chama de "execução terminal da política social".

Sobre esse ponto cabem algumas reflexões: Segundo Costa (1986), os centros de saúde foram criados a partir de meados da década de 1920 e neles os serviços básicos seguiam duas vertentes: a educação sanitária por intermédio de educadores de higiene e a experiência de descentralização do trabalho sanitário em metrópoles. Previa médicos, enfermeiros e visitadores. 
Essa influência resultava do legado

americano de medicina preventiva e comunitária, por conseguinte o assistente social priorizava suas ações no nível curativo e hospitalar, sem influência nos centros de saúde. Como afirma Bravo \& Costa (2007, p.200): “os assistentes sociais não foram absorvidos neste espaço senão muito mais tarde, em 1975".

É relevante para essa pesquisa compreender que o Serviço Social sofreu profundas transformações na área da saúde e seus rumos foram marcados por uma profissão liberal, regulamentada por seus estatutos legais, seu projeto ético-político que atribuem autonomia teórico-metodológica, ético-política e técnicooperativa com rigor analítico e ideológico.

Como resultado, esse estudo pode produzir ao Serviço Social reflexões contínuas sobre a sua prática. Para Marsíglia (2007, p. 386), "a prática profissional representa uma das possibilidades de se produzir conhecimento", tão importante quanto à pesquisa acadêmica concentrada nas Universidades e instituições de pesquisas. É inegável o avanço intelectual da sistematização da prática no Brasil.
De acordo com o pensamento de Santos \& Lanza (2014, p.240), justifica-se a importância dessa discussão visto que "a formação técnica hegemônica das ciências da saúde tem pouca ou nulas aproximações com temas da área social”. Ademais esse estudo tem relevância acadêmica, profissional e social.

Cabe ainda a justificativa de que o Serviço Social é uma profissão voltada à intervenção do social, e participa no processo de produção e reprodução das relações sociais entre Estado e sociedade. Sendo assim, esse profissional está no âmbito das tensões produzidas pelo pensamento neoliberal.

Sequenciamos esse artigo com indicações que buscam responder questionamentos, possibilidades, limites e inquietações que contribuam para a produção científica do tema abordado.

Como pensar no Assistente Social do NASF como matriciador junto a eSF?

Para tanto, o NASF desenvolve trabalho somativo que contempla as dimensões clínicoassistencial e técnico-pedagógica. A primeira recai sobre a ação clínica direta com a população 
de um território e a segunda escora as ações educativas com e para as equipes de saúde (Brasil 2009).

Cabe ressaltar o referencial teóricometodológico do apoio matricial, ou seja, uma equipe de apoiadores solicitados a realizar acompanhamento in loco de situações mais complexas no cotidiano das eSF. E agregando maior capacidade de análise e intervenção sobre as demandas biológicas, sociais e subjetivas dos usuários da saúde.

$\mathrm{Na}$ perspectiva de Santos \& Lanza (2014), apoio matricial é:

Dispositivo que visa a superação das práticas tradicionais em saúde e da racionalidade gerencial hegemônica, por meio de ações de apoio capazes de criar linhas de transversalidade nas estruturas dos serviços e equipes de saúde. (2014, p. 236).

O apoiador matricial é um especialista que possui um núcleo de conhecimento e um perfil distinto dos profissionais de referência, e juntamente com a equipe de referência busca um diálogo compartilhado entre os saberes e outras possibilidades na elaboração de um Projeto Terapêutico Integrado.
Desde a década de 1990 as terminologias "matriciamento" e "apoio matricial" são mencionadas na literatura e documentos institucionais relacionados à APS.

Na compreensão de Barros (2015, p.2848) "matriciar significa compartilhar, apoiar, corresponsabilizar-se por determinada demanda de saúde apresentada por uma pessoa, uma família, ou uma comunidade". Do ponto de vista da organização do trabalho, as ações compartilhadas entre NASF e ESF são consideradas pela referida autora como "estratégia fundamental para desterritorializar os profissionais de seu núcleo de saber específico e favorecer a busca de novas possibilidades de produção de saúde e a consolidação de um novo paradigma/pensamento" (Barros 2015, p. 2848).

\section{CONCLUSÕES}

Frente às ponderações aqui colocadas, cabem algumas considerações que reafirmem à necessidade de impulsionar pesquisas sobre a importância de acúmulo teórico para o profissional da saúde, em particular o Assistente 
Social. A dimensão socioeducativa do Serviço

Social reitera sua intervenção profissional na

dimensão ideopolítica com uma leitura singular dos efeitos do seu trabalho na sociedade e no processo de intervenção no social, devendo introduzir ações que consigam explicar as suas razões e a direção social de suas concepções.

Qualquer que seja o espaço de trabalho, a análise no âmbito das relações sociais, buscar romper com a visão a-histórica e focalista que desestimam o acúmulo teórico e político na profissão. Torna-se necessária a relação de unidade entre teoria e prática, e um profissional versado de ações capazes de avaliar, recriar e estimular mudanças no cotidiano dos indivíduos.

Uma intervenção que abrange mudanças e não o tratamento baseado na relação saúde-

doença-morte, considerando que os determinantes sociais estão evidentes à saúde marcando a esfera da reprodução social. A prática da saúde não pode ser alienante na interpretação pedagógica, e ao longo do crescimento da saúde coletiva, tanto para o profissional da saúde quanto para os usuários da política.
É possível pensar e propor projetos que instrumentalizem a execução do processo de ensinar e aprender de forma densa e abrangente a crianças, adolescentes, adultos, gestantes, idosos e deficientes. Não se esgotam neste artigo novas discussões que aprofundem as dimensões pedagógicas do Assistente Social na saúde. O Núcleo de Apoio à Saúde da Família é um espaço profícuo para o saber compartilhado.

\section{REFERÊNCIAS}

ALVES GG AND AERTS D. 2011. As práticas educativas em saúde e a Estratégia Saúde da Família. In: Ciência e Saúde Coletiva 319-25. Disponível em: http://www.scielo.br/pdf/csc/v16n1/v16n1a34.pd f. Acesso em: 13 de Jan. 2021.

BARROS JO et al. 2015. Estratégia do apoio matricial: a experiência de duas equipes do Núcleo de Apoio à Saúde da Família (NASF) da cidade de São Paulo. In: Ciência e Saúde

Coletiva 2847-2856. Disponível em: www.scielo.br/pdf/csc/v20n9/1413-8123-csc-2009-2847.pdf. Acesso em: 15 de Jan. 2021

BRASIL. 1998. Constituição Federal de 1988. Brasília.

Lei 8.080, de 19 de setembro de 1990. Dispõe sobre as condições para a promoção, proteção e recuperação da saúde, a organização e o funcionamento dos serviços correspondentes e dá outras providências. 1990a. Diário Oficial da União, Brasília, DF, 19 set. Seção 1. Disponível em:

https://www2.camara.leg.br/legin/fed/lei/1990/le i-8080-19-setembro-1990-365093- 


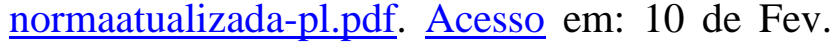
2021

. Lei 8.142, de 28 de dezembro de 1990.

1990b. Dispõe sobre a participação da comunidade na gestão do Sistema Único de Saúde

(SUS \} e sobre as transferências intergovernamentais de recursos financeiros na área da saúde e dá outras providências. Diário Oficial da União, Brasília, DF, 31 dez. Seção 1.

Disponível em: https://servicos2.sjc.sp.gov.br/media/116799/mic rosoft_word_-_lei_n_8142.pdf. Acesso em: 11 de_Jan. 2021.

BRASIL. Ministério da Saúde. 2012. Política Nacional de Atenção Básica/Ministério da Saúde. Secretaria de Atenção à Saúde. Departamento de Atenção Básica. Brasília: Ministério da Saúde.

Disponível

em: http://189.28.128.100/dab/docs/publicacoes/gera 1/pnab.pdf.

Secretaria de Atenção em Saúde. Diretrizes do NASF: Núcleo de Apoio à Saúde da Família. 2009. In: Cadernos de Atenção Básica, $\mathrm{n}^{\circ} 2$.

. Secretaria de Atenção à Saúde. 2014.

Departamento de Atenção Básica. Núcleo de Apoio à Saúde da Família - Volume 1: Ferramentas para a gestão e para o trabalho cotidiano. In: Cadernos de Atenção Básica, no 39.

. Portaria GM No 154. 2008. Criação dos Núcleos de Apoio à Saúde da Família - NASF Republicada em 04 de março.

. Portaria GM No 2.436. (21 de setembro de 2017). Aprova a Política Nacional de Atenção Básica.

BRAVO, MIS. 2007. 2007. Serviço Social e reforma sanitária: lutas sociais e práticas profissionais $2^{\mathrm{a}}$ ed. São Paulo: Cortez.

. Política de Saúde no Brasil. 2007. In:

MOTA. A. E. et al. (Org.). Serviço Social e saúde: formação e trabalho profissional. $2^{\mathrm{a}}$ ed. São Paulo: Cortez, p. 88-110.

BRAVO MIS AND MATOS MC. 2007. Projeto ético-político do serviço social e sua relação com a reforma sanitária: elementos para o debate. In:

MOTA. A. E. et al. (Org.). Serviço Social e saúde: formação e trabalho profissional. $2^{\mathrm{a}}$ ed. São Paulo: Cortez, p. 197-217.

CARTILHA NASF. 2018. Núcleo de Apoio à Saúde da Família no apoio à Regulação Ambulatorial. $1^{\text {a }}$ ed., Rio de Janeiro: Volta Redonda SMS.

COSTA MDH. O Trabalho nos Serviços de Saúde e a Inserção dos(as) Assistentes Sociais. 2007. In: MOTA, A. E. et al. (Org.). Serviço social e saúde: formação e trabalho profissional. $2^{a}$ ed. São Paulo: Cortez, p. 304-351.

COSTA NR. 1986. Lutas urbanas e controle sanitário. Rio de Janeiro, Vozes.

CFESS. 2010. Parâmetros para Atuação de Assistentes Sociais na Política de Saúde. [Brasília]: Conselho Federal de Serviço Social.

Disponível em: http://www.cfess.org.br/arquivos/Parametros_pa ra_a_Atuacao_de_Assistentes_Sociais_na_Saud e.pdf. Acesso em 12 de Jan. 2021.

CONSELHO FEDERAL DE SERVIÇO SOCIAL. 1993. Código de Ética Profissional dos Assistentes Sociais. Resolução CFESS n. 273 de 13 de março de 1993. Alterações introduzidas pelas Resoluções CFESS n. 290/1994 e n.

293/1994. Disponível em:

http://www.cfess.org.br/arquivos/CEP_CFESS-

SITE.pdf. Acesso em: Acesso em: 12 de Jan. 2021.

Conferência Internacional sobre cuidados primários de saúde. 1978. Declaração de AlmaAta, URSS.

FALEIROS VP. 2005. Reconceituação do Serviço Social no Brasil: uma questão em 
movimento? Serviço Social \& Sociedade $\mathrm{n}^{\mathrm{o}} 84, \mathrm{p}$ 21-36. São Paulo: Cortez.

FREIRE P. Pedagogia do oprimido. Rio de Janeiro: Paz e Terra.

IAMAMOTO MV. 2004. A produção de Conhecimento em Serviço Social no Brasil. In: Encontro Nacional de Pesquisadores em Serviço Social (ENPESS) IX, 2004, Porto Alegre. Anais.

. O Serviço Social na contemporaneidade:

trabalho e formação profissional. $12^{\mathrm{a}}$ ed: São Paulo, Cortez, 2007a, p.69.

\section{Serviço Social em tempo de capital}

fetiche: capital financeiro, trabalho e questão social. São Paulo, Cortez, 2007b.

IAMAMOTO MV AND CARVALHO R. 2006. Relações sociais e Serviço Social no Brasil: esboço de uma interpretação históricometodológica. São Paulo: Cortez.

LANZA LMB. 2012. CAMPANUCCI FS AND BALDOW LO. As profissões em saúde e o Serviço Social: desafios para a formação profissional. In: Katálysis, [online], v. 15, n. 2, p. 212-220. Disponível em: https://dialnet.unirioja.es/servlet/articulo?codigo $=4151654$. Acesso em 12 de Jan. 2021.

MACHADO FV et al. 2019. Análise do Deep Learning em cuidados de saúde. Rev. enferm. UFPE on line, p. 1-7. Machado FV, Emmerick LG, Silva RCL, et al. Disponível em: https://doi.org/10.5205/1981-8963.2019.242121. Acesso em: 20 de Dez. 2020.

MARSÍGLIA RMG. 2007. Pesquisa e Sistematização do Trabalho Profissional: orientações básicas para a pesquisa. In: MOTA $\mathrm{AE}$ et al. (Org.). Serviço social e saúde: formação e trabalho profissional. $2^{a}$ ed. São Paulo: Cortez, p. 383-398.

MOURÃO AMA et al. 2007. A formação dos trabalhadores sociais no contexto neoliberal. O projeto das residências em saúde da Faculdade de Serviço Social da Universidade Federal de Juiz de Fora. In: MOTA, A. E. et al. (Org.). Serviço social e saúde: formação e trabalho profissional. $2^{\mathrm{a}} \mathrm{ed}$. São Paulo: Cortez, p. 352-380.

NETTO JP. Capitalismo Monopolista e Serviço Social. São Paulo: Cortez, 1992.

ROSA WAG AND LABATE RC. 2005. Programa Saúde da Família: a construção de um novo modelo de assistência. In: Revista Latinoamericana de Enfermagem, novembrodezembro, 13: 1027-34.

SANTOS ER, LANZA LMB. 2014. O Matriciamento no NASF: interpretações sobre o trabalho do Assistente Social. In: Revista Argumentum. [online], v. 6, n. 2 p. 233-246, 2014. Disponível em: http://www.redalyc.org/articulo.oa?id=47554714 3017. Acesso em: 12 de Jan. 2021.

SANTOS, ER, LANZA, LMB; CARVALHO BG. Educação Permanente em Saúde: a experiência do Serviço Social com Equipes Saúde da Família. In: Textos \& Contextos. [online], v.10, n. 1, p. 15-25, 2011. Disponível em:

http://revistaseletronicas.pucrs.br/fass/ojs/index. $\mathrm{php} /$ fass/article/viewFile/8341/6421. Acesso em: 12 de Jan. 2021. 